\title{
Morphology and Properties of Segmented Polyether Poly(urethane-urea-amide)
}

\author{
Nobuhiko YUI, Kazuhiko NoJIMA, Kohei SANUI, \\ and Naoya OGATA \\ Department of Chemistry, Faculty of Science and Technology, \\ Sophia University, \\ 7-1 Kioi-cho, Chiyoda-ku, Tokyo 102, Japan
}

(Received September 19, 1984)

\begin{abstract}
Segmented polyether poly(urethane-urea-amide) (PEUUA)s containing poly(propylene oxide) (PPO) segments of various molecular weights were synthesized and their morphology and properties were characterized in comparison with the conventional segmented polyether poly(urethane-urea) (PEUU). PEUUAs consisted of two incompatible segments, soft segments with the repeating units of PPO and urethane group, and hard segments composed of urea and amide groups. Characterization of PEUUA was carried out by small-angle X-ray scattering, dynamic mechanical, tensile, and hysteresis measurements. A comparison of PEUUA and PEUU indicated that PEUUA had higher mechanical strength and hysteresis values. These favorable features were considered due to the hard domains composed of strongly hydrogen bonded segments dispersed in the matrix of the soft segments, resulting in hard domain interconnectivity.

KEY WORDS Segmented Polymer / Microphase-Separated Structure / Long Period / Mechanical Strength / Hysteresis /
\end{abstract}

Segmented polyether poly(urethane-urea) (PEUU), commercially available as Biomer, ${ }^{\circledR}$ has been widely applied for cardiovascular prostheses such as blood pumps for artificial heart systems mainly due to its antithrombogenicity and excellent mechanical properties. ${ }^{1,2}$ These unique properties are directly related to the two-phase-separated microstructure, with the semicrystalline hard segment domains acting as reinforcing fillers and as thermally reversible cross-links, which are dispersed in a continuous matrix of the rubbery soft segments. The driving force for this phase separation is primarily the formation of intermolecular hydrogen bonding network. ${ }^{3}$ The first study on PEUU as biocompatible material was made by Lyman et al. ${ }^{1}$ They assumed that the blood compatibility might closely depend on the microstructure of these PEUUs, and that the two phase morphology for antithrombo- genicity should have the domains of $3-10 \mathrm{~nm}$ in size. ${ }^{4}$ Recently, a large number of factors influencing the blood compatibility have been reported for the properties of PEUU elastomers. $^{5-8}$

In our previous studies on the adhesion of blood cells on segmented polyether-amides as other type of segmented polymers, we suggested that the size and distribution of microdomains in the segmented polymers might be one of the determining factors in antithrombogenicity. ${ }^{9,10}$ In this material, the crystallization was considered to be the major factor for the phase separation, resulting in unique crystalline lamella growth. ${ }^{11}$ Of course, the amide group as well as the urea one is capable of forming intermolecular hydrogen bonds, which produce high strength and toughness.

In this paper, we made the material characterization of a newly synthesized segmented 
polymer with amide groups in the hard segments with the above backgrounds. The present results showed improvements of mechanical strength and domain interactions by the incorporation of amide groups into the hard segment in PEUU.

\section{EXPERIMENTAL}

\section{Preparation of Reagents}

Poly(propylene oxide) (PPO) of 1170, 1450, and 2000 of molecular weight (MW), supplied by Dow Chemical Japan Co. and Daiichi Kogyo Seiyaku Co., were dehydrated in vacuo at $60^{\circ} \mathrm{C}$ for $48 \mathrm{~h}$. Hexamethylenediamine (HMD), 4,4'-diphenylmethane diisocyanate (MDI), $\quad N, N^{\prime}$-dimethylacetamide (DMAc), and $N$-methyl-2-pyrrolidone (NMP) were purified by distillation. Sebacic acid was used as received.

Diamino oligoamide (DAOA) as the chain extender having amide groups was prepared by reacting sebacic acid with an excess amount of HMD. The molar ratio of sebacic acid and HMD was $1: 10$, and the reaction was performed at $270^{\circ} \mathrm{C}$ for $5 \mathrm{~h}$ under high pressure $(30$ $\mathrm{kg} \mathrm{cm}^{-3}$ ) of dry nitrogen. The mixture was poured into water, and the precipitate was recrystallized from methanol. The product was then dried in vacuo at $40^{\circ} \mathrm{C}$ for $24 \mathrm{~h}$ to give a white powder; yield $11.4 \%$. End groups of DAOA were determined by nonaqueous titrimetry. In the titration for the amino group, about $0.15 \mathrm{~g}$ of DAOA was immersed in $10 \mathrm{~cm}^{3}$ of acetic acid and titrated with a $N / 10$ dioxane solution of $\mathrm{HClO}_{4}$, using crystal violet as an indicator. Carboxyl group determination was carried out by immersing $0.10 \mathrm{~g}$ of DAOA in $10 \mathrm{~cm}^{3}$ of benzyl alcohol and by titrating with a $N / 10 \mathrm{KOH}$ solution of methanol and ethylene glycol, which was prepared from $1 N \mathrm{KOH}$ solution of methanol, using phenolphthalein as an indicator. The MW and functionality of DAOA were calculated by the following equations:

$$
\begin{aligned}
& \text { MW of DAOA }(M)=\frac{2 m}{P+q}, \\
& \text { functionality of DAOA }(\mathrm{f})=\frac{P}{m / M},
\end{aligned}
$$

where $m$ is a weight of DAOA used, $P$ and $q$, a molar quantity of amino and carboxyl groups, respectively. From these calculations, $M$ was 490 , and $f$ was 1.94 .

\section{Preparation of Segmental Polyether Poly- (urethane-urea-amide) (PEUUA)}

Structural formula of PEUUA is represented in Figure 1. The PEUUA used in this study were synthesized by the reaction of prepolymer as shown in Figure 2. PPO and MDI were placed in a four-necked, roundbottomed flask equipped with a stirrer, a condenser, and a drying tube. After reacting at $80^{\circ} \mathrm{C}$ for $8 \mathrm{~h}$, the mixture was cooled to room temperature, and a $10 \mathrm{wt} \%$ DAOA solution in $7 \mathrm{wt} \% \mathrm{LiCl}-\mathrm{NMP}$ was added to the flask. The reaction mixture was stirred at about $0^{\circ} \mathrm{C}$ for $3 \mathrm{~h}$. The entire synthesis was performed under

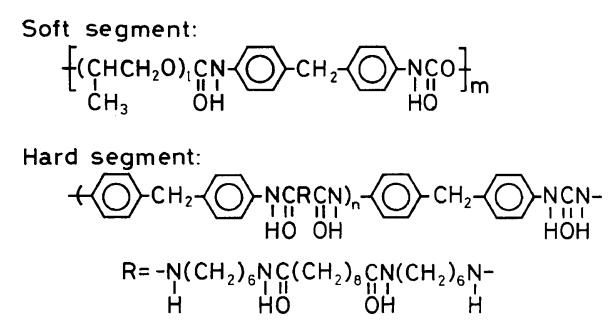

Figure 1. Structural formula of PEUUA.

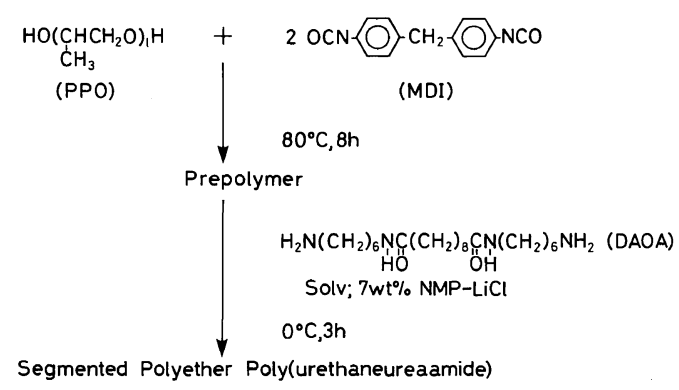

Figure 2. Synthetic route of PEUUA. 
a continuous purge of dry nitrogen. The molar ratio of MDI, PPO, and DAOA were $2: 1: 1$, respectively. The polymers obtained were precipitated in acetone, and then dried in vacuo for 1 week.

Conventional PEUUs as a control sample were also prepared according to the above procedure, in which HMD was used as a chain extender.

For convenience, PEUUAs and PEUUs are designated by a three sequence code such as PEUUA-24-1170, where 24 refers to the weight percent of the hard segment and 1170 to the MW of PPO segment.

\section{Small-Angle X-Ray Scattering ( $S A X S$ )}

SAXS was recorded photographically using a Rotaflex (Rigakudenki RU-200) with nickelfiltered $\mathrm{Cu}-K_{\alpha}$ radiation operated at $50 \mathrm{kV}$ and $200 \mathrm{~mA}$. The sample films used were made by solution casting of $5 \mathrm{wt} \%$ copolymer solution in $m$-cresol on glass plates and then dried in vacuo at $60^{\circ} \mathrm{C}$.

\section{Dynamic Mechanical Measurement}

Measurement was made on a Vibron Dynamic Viscoelastometer (Toyo Baldwin DDV-II-EA). The temperature range was from $-120^{\circ} \mathrm{C}$ to $180^{\circ} \mathrm{C}$ under a dry nitrogen atmosphere and frequency employed was $11 \mathrm{~Hz}$. The sample films were prepared by the procedure described above.

\section{Tensile Properties}

Uniaxial stress-strain and stress-hysteresis data were taken on a Autograph (Shimadzu Co., IS-5000) at room temperature, with a crosshead speed of $300 \mathrm{~mm} \mathrm{~min}^{-1}$ and initial gauge length of $20 \mathrm{~mm}$. The percent hysteresis for a given cycle was calculated from the ratio of the area bounded by the loading-unloading curves to the total area under the loading curve. The sample films were made according to the above procedure.

\section{RESULTS AND DISCUSSION}

\section{Preparation of PEUUA}

The IR spectra of PEUUA-24-1170 and PEUU-24-1170 are shown in Figure 3. PEUUA-24-1170 shows main peaks at 3250 $\mathrm{cm}^{-1}$ for the hydrogen-bonded $\mathrm{NH}$ group, $1720 \mathrm{~cm}^{-1}$ for the free urethane carbonyl, $1640 \mathrm{~cm}^{-1}$ for the hydrogen-bonded urea or amide carbonyl, and $1540 \mathrm{~cm}^{-1}$ for the hydrogen-bonded NH group, which indicated the formation of urethane, urea, and amide linkages. A comparison of the PEUUA and PEUU showed that the shift of the hydrogenbonded NH peak from 3300 to $3250 \mathrm{~cm}^{-1}$ and stronger peaks of 1640 and $1540 \mathrm{~cm}^{-1}$ were attributed to the hydrogen-bonded $>\mathrm{C}=$ $\mathrm{O} \cdots \mathrm{H}-\mathrm{N}<$ linkage existed in the hard segments of PEUUA.

Results of the polymerization are summarized in Table I. The results of elemental analysis of the copolymers were in close agreement with the expected values. These results support the formation of the PEUUAs as the designed structure which was chain-extended by DAOA.

\section{Material Characterization of PEUUA}

It is well known that segmented polymers have a microphase-separated structure composed of soft and hard segments. The SAXS results can quantitatively be interpreted in terms of structural sub-units of several dozen nanometers in magnitude. The long period obtained from the SAXS patterns thus provides information on the effective density differences between the soft and hard segment phases. Table II shows the results of SAXS measurements for PEUUAs and PEUUs. The existence of the long period in both PEUUAs and PEUUs means the formation of a microphase-separated structure. When plots of the long period of PEUUA and PEUU against the MW of PPO segment in the copolymers are extrapolated to zero PPO of MW, the magnitude of long period around $9.7 \mathrm{~nm}$ and 


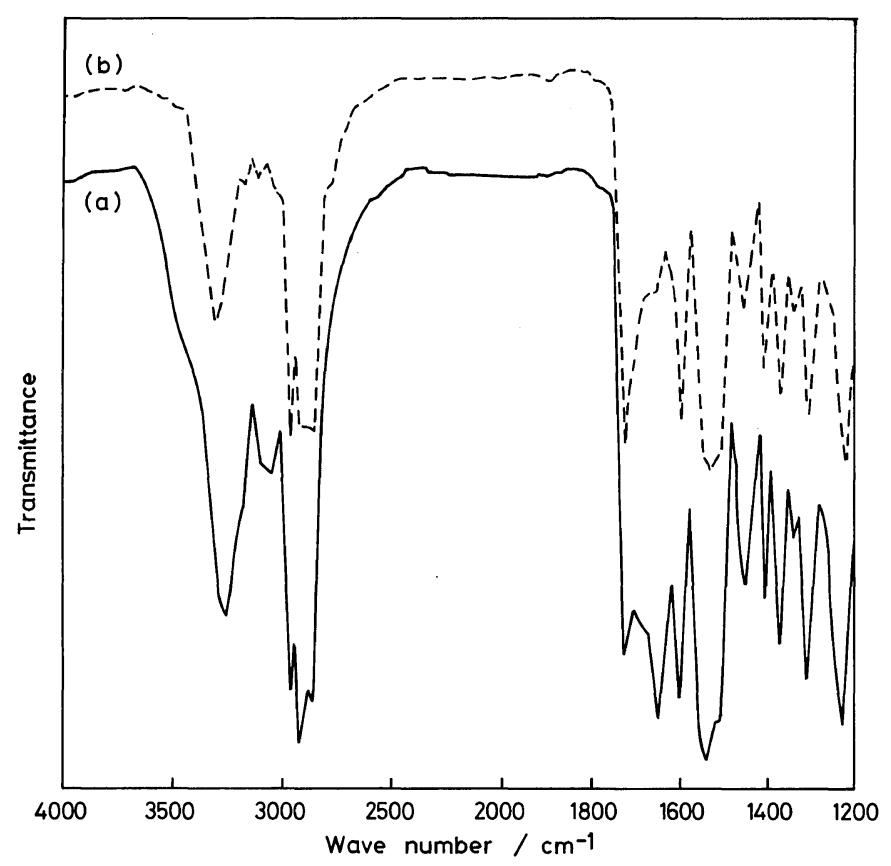

Figure 3. IR spectra of (a) PEUUA-24-1170 and (b) PEUU-24-1170.

Table I. Synthesis of segmented polyether poly(urethane-urea-amide)

\begin{tabular}{|c|c|c|c|c|c|c|c|c|}
\hline \multirow{2}{*}{ Sample } & \multicolumn{4}{|c|}{ Elemental analysis $/ w t \%$} & \multirow{2}{*}{$\begin{array}{l}\text { Weight percent of } \\
\text { hard segment }\end{array}$} & \multirow{2}{*}{$\begin{array}{l}\text { Molecular weight } \\
\text { of PPO }\end{array}$} & \multirow{2}{*}{$\frac{\text { Yield }}{\%}$} & \multirow{2}{*}{$\eta_{\mathrm{sp}} / c^{\mathrm{b}}$} \\
\hline & & $\mathrm{C}$ & $\mathrm{H}$ & $\mathrm{N}$ & & & & \\
\hline \multirow[t]{2}{*}{ PEUUA-24-1170 } & Found & 59.9 & 8.6 & 6.6 & 23.6 & 1170 & 95.6 & 1.3 \\
\hline & Calcd & 64.0 & 10.1 & 5.3 & & & & \\
\hline \multirow[t]{2}{*}{ PEUUA-21-1450 } & Found & 59.1 & 8.9 & 6.0 & 20.9 & 1450 & 83.8 & 0.80 \\
\hline & Calcd & 63.8 & 10.1 & 4.9 & & & & \\
\hline \multirow[t]{2}{*}{ PEUUA-12-2000 } & Found & 60.2 & 9.1 & 6.6 & 12.3 & 2000 & 46.3 & 1.2 \\
\hline & Calcd & 63.5 & 10.2 & 3.8 & & & & \\
\hline \multirow[t]{2}{*}{ PEUU-24-1170 } & Found & 64.2 & 8.9 & 4.1 & 23.5 & 1170 & 84.4 & 1.5 \\
\hline & Calcd & 63.4 & 10.4 & 4.6 & & & & \\
\hline \multirow[t]{2}{*}{ PEUU-14-1450 } & Found & 61.0 & 8.9 & 4.9 & 14.0 & 1450 & 89.7 & 1.5 \\
\hline & Calcd & 63.2 & 10.1 & 4.0 & & & & \\
\hline \multirow[t]{2}{*}{ PEUU-14-2000 } & Found & 64.0 & 9.2 & 3.4 & 13.7 & 2000 & 85.9 & 2.3 \\
\hline & Calcd & 63.0 & 10.1 & 3.2 & & & & \\
\hline
\end{tabular}

a Weight percent of hard segment in the copolymer was determined by elemental analysis.

b $0.1 \mathrm{~g} / 10 \mathrm{~cm}^{3}$ in $m$-cresol at $30^{\circ} \mathrm{C}$.

$10.0 \mathrm{~nm}$ might give the size of the hard segment domain in PEUUA and PEUU. ${ }^{12}$ The size of the soft segment domain which is determined as the difference between the long period of the copolymer and the size of the hard seg- ment domain increased slightly with increasing the MW of PPO segment, and the long periods for PEUUAs were closely related to those for PEUUs. Therefore, the size and distribution of the soft and hard segment do- 
Table II. Microstructure of segmented polyether poly(urethane-urea-amide)

\begin{tabular}{ccccc}
\hline & Long period $^{\mathrm{a}}$ Sample & \multicolumn{2}{c}{ Domain size/nm } \\
\cline { 2 - 2 } \cline { 5 - 5 } & $\mathrm{nm}$ & & $\begin{array}{c}\text { Hard } \\
\text { segment }\end{array}$ & $\begin{array}{c}\text { Soft } \\
\text { segment }\end{array}$ \\
\cline { 5 - 5 } & & & 9.7 & 1.0 \\
PEUUA-24-1170 & 10.7 & & 9.7 & 1.1 \\
PEUUA-21-1450 & 10.8 & & 9.7 & 1.8 \\
PEUUA-12-2000 & 11.5 & & 10.0 & 0.5 \\
PEUU-24-1170 & 10.5 & & 10.0 & 0.8 \\
PEUU-14-1450 & 10.8 & & 10.0 & 1.1 \\
PEUU-14-2000 & 11.1 & &
\end{tabular}

a Long period of copolymer was determined from SAXS.

mains may not be drastically changed by the chemical structure of the hard segments, indicating that PEUUA have the same morphology as PEUU in regard to the extent of phase separation between the soft and hard segments.

Figures 4 and 5 show the temperature dependence of the storage modulus $\left(E^{\prime}\right)$ and loss modulus $\left(E^{\prime \prime}\right)$ of PEUUAs and PEUUs, respectively. These figures exhibited a mechanical relaxation region due to micro-Brownian motion of the PPO segments in each copolymer. The loss peaks in $E^{\prime \prime}$ shifted to a lower temperature side and narrowed in width with increasing the MW of PPO segment. This indicates that the phase separation between the soft and hard segments became more distinct with an increase in MW of the PPO segment. Further, the magnitude of $E^{\prime}$ for PEUUA was larger than that for PEUU, and disappearance of a plateau region around room temperature in the PEUUA samples was observed except for PEUUA-12-2000. This suggests that the modulus was improved by incorporating amide groups into the hard segment. Each series of copolymers showed that the highest modulus around room temperature was obtained for the copolymers having a PPO of MW 1450. This result indicates that the copolymers having the PPO of MW 1450 probably have a higher content of "effective"

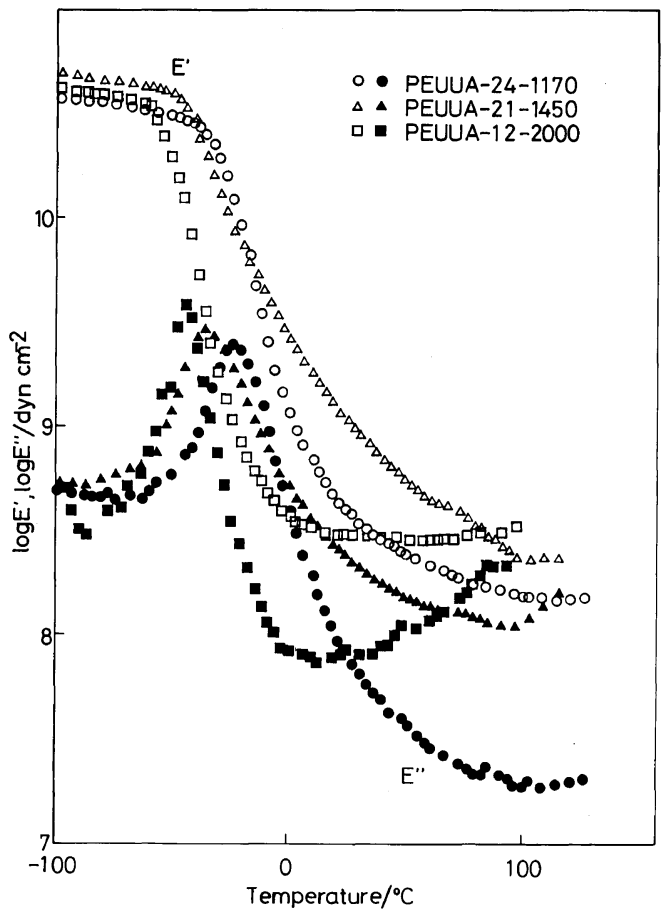

Figure 4. Temperature dependences of $E^{\prime}$ and $E^{\prime \prime}$ of PEUUA. open plot, $E^{\prime}$; closed plot, $E^{\prime \prime}$.

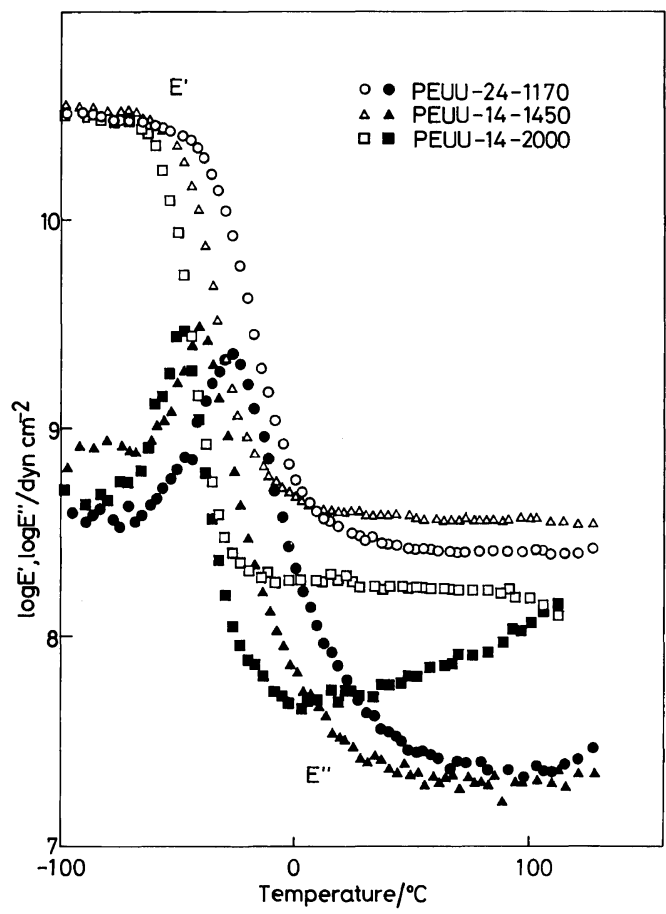

Figure 5. Temperature dependences of $E^{\prime}$ and $E^{\prime \prime}$ of PEUU. open plot, $E^{\prime}$, closed plot, $E^{\prime \prime}$. 


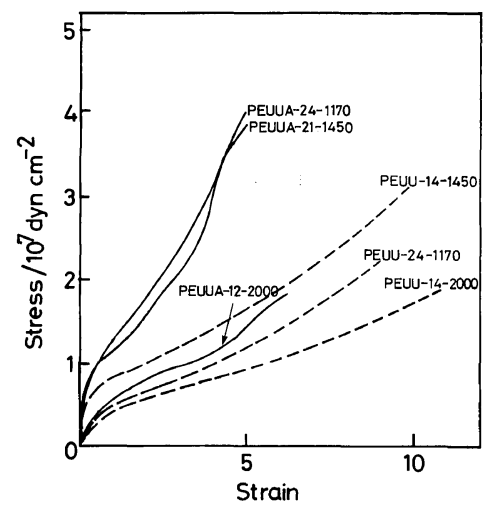

Figure 6. Stress-strain curves for PEUUA and PEUUs.

Table III. Tensile properties of segmented polyether poly(urethane-urea-amide)

\begin{tabular}{|c|c|c|c|}
\hline \multirow{2}{*}{ Sample } & Modulus & Strength & \multirow{2}{*}{$\begin{array}{c}\begin{array}{c}\text { Elongation } \\
\text { at break }\end{array} \\
\%\end{array}$} \\
\hline & $10^{7} \mathrm{dyn}^{-2}$ & $10^{7} \mathrm{dyn}_{\mathrm{cm}^{-2}}$ & \\
\hline PEUUA-24-1170 & 13.8 & 3.99 & 495 \\
\hline PEUUA-21-1450 & 8.92 & 4.06 & 495 \\
\hline PEUUA-12-2000 & 2.17 & 1.80 & 615 \\
\hline PEUU-24-1170 & 4.57 & 2.25 & 910 \\
\hline PEUU-14-1450 & 2.85 & 3.10 & 990 \\
\hline PEUU-14-2000 & 2.40 & 1.84 & 1075 \\
\hline
\end{tabular}

hard segments which enhance physical crosslinking effects.

The tensile behavior of segmented polymers is generally considered to depend on size, shape, and concentration of the hard segment domains, and the intermolecular hydrogen bonds within the hard segment domains. ${ }^{13}$ The stress-strain curves of the PEUUAs and PEUUs are shown in Figure 6. Table III summarizes the results of tensile measurements. An increase in the hard segment content in both PEUUAs and PEUUs led to higher modulus and lower elongation at break.

On the other hand, an increase in the strength was observed for the copolymers with the PPO MW of 1450 . In comparison with PEUUs, PEUUAs exhibited higher moduli and strength, and lower elongations at break,

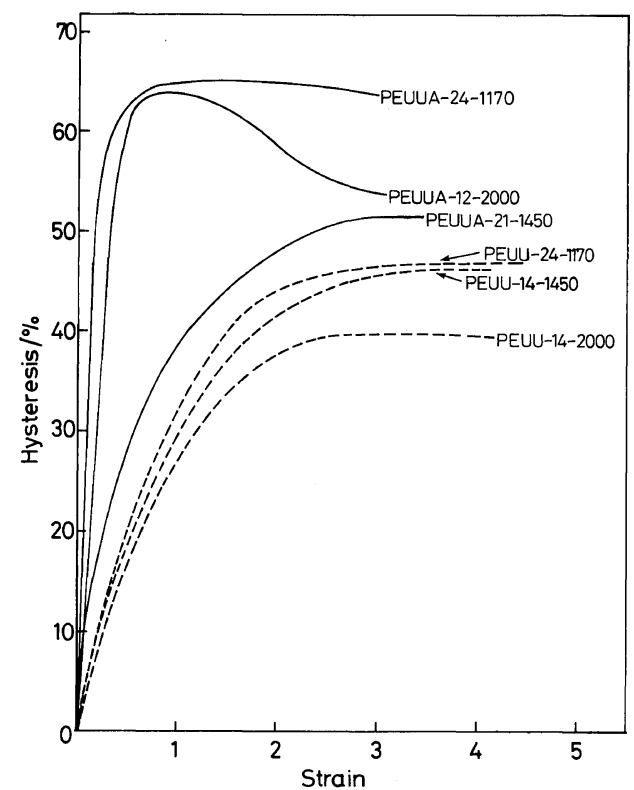

Figure 7. Percent hysteresis as a function of strain in PEUUAs and PEUUs.

indicating that the mechanical strength of the copolymer was improved by the introduction of amide groups into the hard segment. These features are presumably due to the hard domains composed of strongly hydrogen bonded segments which are dispersed in the matrix of the soft segments.

The stress hysteresis behavior of these copolymers is also closely related to the domain morphology and degree of phase separation. ${ }^{13-15}$ The results of the stress hysteresis experiments for PEUUAs and PEUUs are shown in Figure 7. In the case of PEUUs, all the samples exhibited similar hysteresis profiles, in which the hysteresis value stayed constant between $40-50 \%$ with an increase in the elongation. In contrast with PEUUs, PEUUAs had relatively high hysteresis values. PEUUA-24-1170 and -12-2000 showed a quickly rising hysteresis value of about $65 \%$; the former kept constant level, and the latter leveled off at $55 \%$ with a further increase in the elongation. In general, a high level of hysteresis at small strains may result from the 
disruption of hard domain interconnectivity. That is, clustering of hard segment domains does not allow for large elastic deformation, causing the high hysteresis at small strains. ${ }^{15}$ Therefore, the high hysteresis value would be ascribed to the disruption of hard domain interconnectivity occurring at the interphase boundaries with the growth of micro-craze which results in high energy absorption. Presumably, the structure of the copolymer in the solution casting process, in which hydrogen bonding interaction between the hard segments and solvent is dominant, leads to enhanced hard domain inteconnectivity in solid state.

\section{CONCLUSION}

A series of segmented polyether poly(urethane-urea)s having amide groups in the hard segment were synthesized and their morphology and properties were characterized. The mechanical strength of the copolymer was improved by the incorporation of amide groups into the hard segment, although the degree of phase separation between the soft and hard segments depended primarily upon the MW of PPO segment. Moreover, the copolymer having amide groups exhibited enhanced energy dissipation. These findings suggest that the hard domain interconnectivity was attained by the presence of amide groups in hard segment domains.

Studies with antithrombogenic properties of PEUUAs are now in progress, and it was found that these PEUUAs exhibit the suppressive effect of blood platelet adhesion on the copolymer surfaces. These characteristics will be reported in another paper.

Acknowledgment. The authors are grateful to Prof. Dr. Tisato Kajiyama, and Dr. Atsushi Takahara, Kyushu University, for their advice and assistances in carrying out the SAXS measurement, and to Mr. Atsushi Kasai and Miss Tatsuki Oomiyama, Mitsubishi Chemical Industry Co., for expediting the dynamic mechanical measurements. Grateful acknowledgments are made to Dr. Kazunori Kataoka and Dr. Teruo Okano, Tokyo Women's Medical College, for their valuable comments on the molecular design of the copolymer. This study was financially supported by the Ministry of Education, Japan (Special Project Research, "Design of Multiphase Biomaterials").

\section{REFERENCES}

1. D. J. Lyman, C. Kwann-Gett, H. H. J. Zwart, A. Bland, N. Eastwood, J. Kawai, and W. J. Kolff, Trans. ASAIO, 17, 456 (1971).

2. J. M. Boretos, W. S. Pierce, R. E. Baire, A. F. Leroy, and H. J. Donachy, J. Biomed. Mater. Res., 9, 327 (1975).

3. Y. J. Chang and G. L. Wilkes, J. Polym. Sci., Polym. Phys. Ed., 13, 455 (1975).

4. D. J. Lyman, K. Knutson, B. McNeill, and K. Shibatani, Trans. ASAIO, 21, 49 (1975).

5. A. Takahara, J. Tashita, T. Kajiyama, and $\mathbf{M}$. Takayanagi, Rep. Prog. Polym. Phys. Jpn., 24, 737 (1981).

6. M. D. Lelah, L. K. Lambrecht, B. R. Young, and S. L. Cooper, J. Biomed. Mater. Res., 17, 1 (1983).

7. B. D. Ratner, "Physicochemical Aspects of Polymer Surfaces," Vol. 2, K. L. Mittal, Ed., Plenum Press, New York, N. Y., 1983, p 969.

8. A. Takahara, J. Tashita, T. Kajiyama, and M. Takayanagi, "International Progress in Urethanes," Vol. 4, K. Ashida and K. C. Frisch, Ed., Technomic Press, Westport, in press.

9. N. Yui, J. Tanaka, K. Sanui, N. Ogata, K. Kataoka, T. Okano, and Y. Sakurai, Polym. J., 16, 119 (1984).

10. N. Yui, T. Oomiyama, K. Sanui, N. Ogata, K. Kataoka, T. Okano, and Y. Sakurai, Makromol. Chem., Rapid Commun., 5, 805 (1984).

11. N. Yui, J. Tanaka, K. Sanui, and N. Ogata, Makromol. Chem., 185, 2259 (1984).

12. I. Kimura, H. Ishihara, H. Ono, N. Yoshihara, S. Nomura, and H. Kawai, Macromolecules, 7, 355 (1974).

13. C. B. Wang and S. L. Cooper, Macromolecules, 16, 775 (1983).

14. C. S. P. Sung, T. W. Smith, C. B. Hu, and N. H. Sung, Macromolecules, 12, 538 (1979).

15. J. A. Miller, K. K. S. Hwang, and S. L. Cooper, J. Macromol. Sci. Phys., B22, 321 (1983). 